Research Paper

\title{
Life Cycle Assessment of Ball Bladder Production With and Without Recycled Rubbers
}

\author{
Bahareh Mohsenirad $^{1}$ (D), Ebrahim Fataei $^{1^{*}}$ (D)
}

1. Department of Environmental Engineering, Faculty of Basic Sciences, Ardabil Branch, Islamic Azad University, Ardabil, Iran.

\begin{tabular}{|l|l|}
\hline $\begin{array}{c}\text { Use your device to scan } \\
\text { and read the article online }\end{array}$ & $\begin{array}{l}\text { Crtation Mohsenirad B, Fataei E. Life Cycle Assessment of Ball Bladder Production With and Without Recycled Rubbers. } \\
\text { Journal of Advances in Environmental Health Research. 2021; 9(3):183-190. http://dx.doi.org/10.32598/JAEHR.9.3.1184 }\end{array}$ \\
doi http://dx.doi.org/10.32598/JAEHR.9.3.1184
\end{tabular}

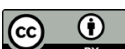

Article info:

Received: 15 Apr 2020

Accepted: 23 Jun 2020

Publish: 01 Jul 2021

\section{Keywords:}

Life cycle assessment, Natural rubber, Recycled rubber, Ball production, SimaPro software

\section{ABSTRACT}

Background: Environmental issues such as global warming and ozone depletion are one of the most controversial concerns of scientists due to their several potential impacts on the earth as a result of long-term emission of greenhouse gases, mainly $\mathrm{CH} 4$ and $\mathrm{CO} 2$. Evidence of greenhouse gas emissions during rubber production provides important and useful data for Life Cycle Assessment (LCA). The present study aimed to reduce the emission rate of greenhouse gases in the ball bladder production process using natural rubber in combination with recycled rubber.

Methods: In this regard, a LCA in SimaPro 8.0.1 software using CML2001 method was conducted on data related to the resources, chemicals, raw materials and energy consumption during ball manufacturing in Tanin Peak Sabalan Factory, Ardabil, Iran.

Results: Our findings revealed that the ball bladder with natural rubber had the largest contribution to the ozone layer depletion $(39.2 \%)$ and global warming $(41.1 \%)$, while the bladder with both recycled and natural rubbers had an impact of $27.9 \%$ and $29.5 \%$, respectively.

Conclusion: In conclusion, the ball bladder with both recycled and natural rubbers is less ecodestructive than that the bladder with only natural rubber.

\section{Introduction}

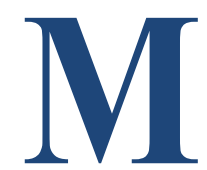

odern societies need to be analyzed environmentally for all processes, products or services. For example, the rubber production has negative consequences on the health of all living things. In fact, the environment is where all living and non-living things have a role; thereby, everyone need to be concerned about the environment. Natural rubber is a renewable resource and a key raw product in the global economy, which is present in many common items. Over $90 \%$ of the global natural rubber production originates in tropical Asia. According to the governmental and private companies, the rubber industries, as well as the rubber product traders, rubber cultivation is climate-smart and environmentally friendly. The manufacturing of sports balls by relative replacement of natural rubber with recycled rubber can be significant with the least environmental impact. Basic polymers and ingre-

\section{* Corresponding Author:}

Ebrahim Fataeim, PhD.

Address: Department of Environmental Engineering, Faculty of Basic Sciences, Ardabil Branch, Islamic Azad University, Ardabil, Iran.

Phone: +98 (914) 3549400

E-mail: eafataei@gmail.com 
dients used for making rubber products, either alone or in combination with other materials, can produce some carcinogenic gases and fumes during mixing, vulcanization process and even during storage. Moreover, chemical dusts come into contact with air and some get contaminated in water; therefore, directly or indirectly affect living things. Waste management is a major concern in the rubber industry.

Life Cycle Asessment (LCA) is an approach relative to a Functional Unit (FU). All subsequent analyses are harmonized with the FU, as all inventory inputs and outputs of the life cycle, and the results are associated with FU [1-7]. A FU is a reference unit by which the performance of a product systems is measured. It is used for quantitative assessment of the performance of production systems [7]. For LCA, system boundary should also be determined with high accuracy, otherwise working for researchers will become difficult because of extensive life cycle, inputs and outputs $[8,9]$. There have been a number of studies on the recycling of waste tires, while some of them have focused on improved burning rate, cost-effectiveness, and physical properties of the recycled tires such as resistance to crack propagation, tear resistance, and tensile strength [2-4]. Some studies have focused on producing fuel from waste tires aiming to further diminish the potential environmental contributions to the impact categories such as energy demand, use of iron ore, global warming, acidification, eutrophication, smog formation, and respiratory effects $[5,7]$. Since natural rubber is one of the main raw materials used in sports ball production and its supply involves high economic inputs as well as harsh environmental issues, this study aims to investigate the possibility of using natural rubber in combination with recycled rubber in manufacturing of sports balls to reduce adverse environmental impacts and production costs. We compare the environmental impacts of two types of constituent materials of sport balls including bladder with natural rubber and bladder with recycled+natural rubbers.

\section{Materials and Methods}

\section{Functional unit and system boundary}

In this study, a FU of 1-kg bladder was used based on which the processes of ball manufacturing can be compared. The system boundary for LCA using bladder with natural rubber and bladder with recycled+natural rubbers was the main process of ball manufacturing which is shown in Figure 1.

\section{Inventory}

Inventory process, which is a time-consuming operation, is done in different ways and methods depending on the purpose and scope of waste disposal. In this study, for LCA, data collection was conducted to quantify all inputs and outputs related to ball manufacturing according to International Organization for Standardization (ISO). Inventory flow of sports ball manufacturing was created based on the available generic data, which included the energy and material inputs and the environmental releases. After direct observation, their values were calculated for $1 \mathrm{Kg}$ of bladder. Furthermore, the data on chemical emissions and consumption were collected including global data such as abiotic depletion, global warming, human toxicity and photochemical oxidation as well as local data such as acidification and lake utrification. SimaPro software was used to modify the data based on the characteristics of the sports ball manufacturing. It is one of the most useful and comprehensive applications for LCA. It is used as a professional tool for analyzing the environmental aspects of products or services $[10,11]$. The software runs in a systematic and permanent way, such that it can provide the best solutions for the project $[3,12]$. The CML2001 method was used to analyze the modified data [3]. This is a novel method for the implementation of ISO standards [11]. In this method, the results can be categorized using the extent of their impact in different ways. The impact categories in this method are abiotic depletion, fossil fuels, global warming, ozone layer depletion, human toxicity, fresh water aquatic eco-toxin, marine aquatic terrestrial, terrestrial toxicity, photochemical oxidation, and acidification $[3,12]$. The inventory for the various processes of sports ball manufacturing is presented in Table 1 .

\section{Results and Discussion}

\section{Bladder with natural rubber}

As shown in Figure 2, the natural rubber had the highest contributions to various impact categories, where the highest contribution was to eutrophication (96.7\%). The synthetic rubber accounted for the highest contributions to various impact categories, including terrestrial toxicity $(28.2 \%)$. In the global warming and ozone layer depletion categories, natural rubber had an impact of $41.1 \%$ and $39.2 \%$, respectively. Therefore, the natural rubber can enhance greenhouse gas emissions by affecting the ozone layer depletion and global warming Table 2.

\section{Bladder with recycled+natural rubbers}

As can be seen in Figure 3, in the ozone layer depletion and global warming categories, the bladder with recycled+natural rubbers had an impact of $29.5 \%$ and $27.9 \%$, respectively. Furthermore, the contribution of synthetic rubber to the impact category of resource de- 


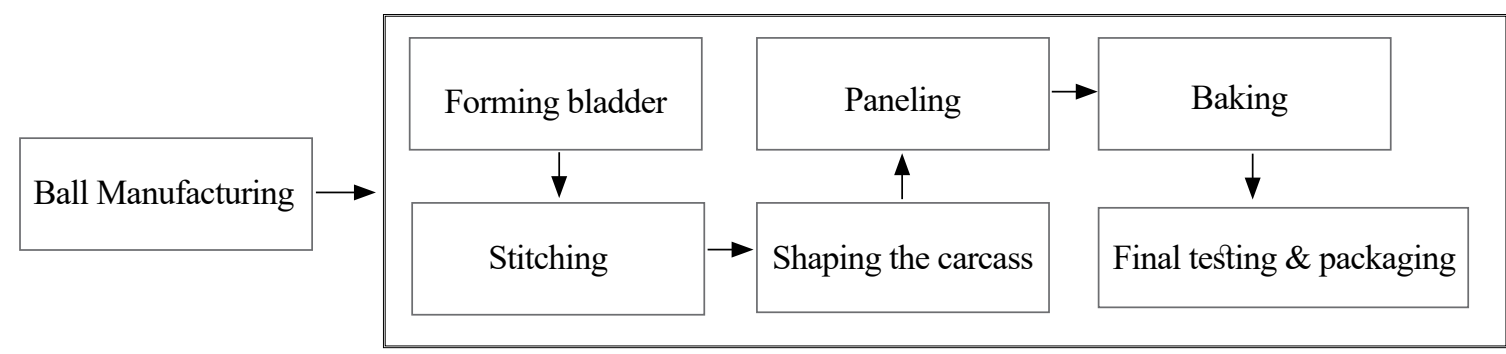

Figure 1. System boundary for LCA of ball manufacturing using bladder with natural rubber and bladder with recycled+natural rubbers

pletion was $69.7 \%$. The values of each impact categories using the bladder with recycled+natural rubbers are presented in Table 3.

Comparing the environmental impacts of ball bladders with and without recycled rubbers

The comparison of the two types of ball products revealed that the ball bladders with recycled+natural rubbers had lower contributions to the impact categories than those with natural rubber except in the category of photochemical oxidation (Figure 4). More specifically, contributions to resource depletion and fossil fuel depletion using bladder with natural rubber were $100 \%$ compared to bladder with recycled+natural rubbers whose contributions were $94.6 \%$ and $82.8 \%$, respectively. Furthermore, the ball bladder with recycled rubber had the lowest impact on the production of greenhouse gases compared to the ball bladder without recycled rubber.
To our knowledge, this is the first LCA study that focuses on optimal combination of natural and recycled rubbers for the production of sport balls. We found no other study that can be fully comparable to our study regarding the recycled rubbers. Photochemical oxidation can lead to the formation of photochemical smog, slow growth of plants and crops by damaging their leaves, accelerating the aging of tire and cord covers, and weakening of the integrity of fabrics. Thus, the photochemical oxidation can be a major drawback for the production of ball bladders with recycled+natural rubbers. With $100 \%$ contributions to all impact categories except in photochemical oxidation, the ball bladder with natural rubber can more undesirable impact on terrestrial and aquatic ecosystems, which makes it an environmentally harmful material. The reasons to why bladder with recycled+natural rubbers was superior include less power consumption in baking process, high air retention capability, and use of recycled waste tire to partially replace natural rubber. There are two environmental benefits of using recycled

Table 1. Inventory for ball manufacturing using bladder with natural rubber and bladder with recycled+natural rubbers

\begin{tabular}{|cccc}
\hline $\begin{array}{c}\text { Material Inputs and Environmental } \\
\text { Releases }\end{array}$ & $\begin{array}{c}\text { Reclaimed Natural Rubber } \\
\text { Without Recycled Rubber }\end{array}$ & $\begin{array}{c}\text { Reclaimed Natural Rubber } \\
\text { With Recycled Rubber }\end{array}$ & Unit \\
\hline Bladder & 51240 & 16000 & $\mathrm{~g}$ \\
\hline Natural rubber & 26000 & 7000 & $\mathrm{~g}$ \\
\hline Synthetic rubber & 6500 & 16000 & $\mathrm{~g}$ \\
\hline Carbon & 16000 & 280 & $\mathrm{~g}$ \\
\hline Stearic acid & 440 & 560 & $\mathrm{~g}$ \\
\hline Zinc oxide & 1600 & 600 & $\mathrm{~g}$ \\
\hline Paraffin & 700 & 600 & $\mathrm{~g}$ \\
\hline Recycled rubber & 0 & 11000 & $\mathrm{~g}$ \\
\hline Calcium carbonate & 0 & 16000 & $\mathrm{~g}$ \\
\hline Electricity & 0.34 & 0.3 & $\mathrm{Kw} / \mathrm{h}$ \\
\hline Toluene & 1.1 & 0.99 & $\mathrm{mg} / \mathrm{L}$ \\
\hline Heptane & 1.17 & 1 & $\mathrm{mg} / \mathrm{L}$ \\
\hline M-xylene & 0.07 & 0.03 & $\mathrm{mg} / \mathrm{L}$ \\
\hline P-xylene & 0.07 & 0.03 & $\mathrm{mg} / \mathrm{L}$ \\
\hline Methyl cyclohexane & 1.76 & 1.2 & $\mathrm{mg} / \mathrm{L}$ \\
\hline 3,4-Dimethyl cyclohexane & 2.6 & 2 & $\mathrm{mg} / \mathrm{L}$ \\
\hline
\end{tabular}




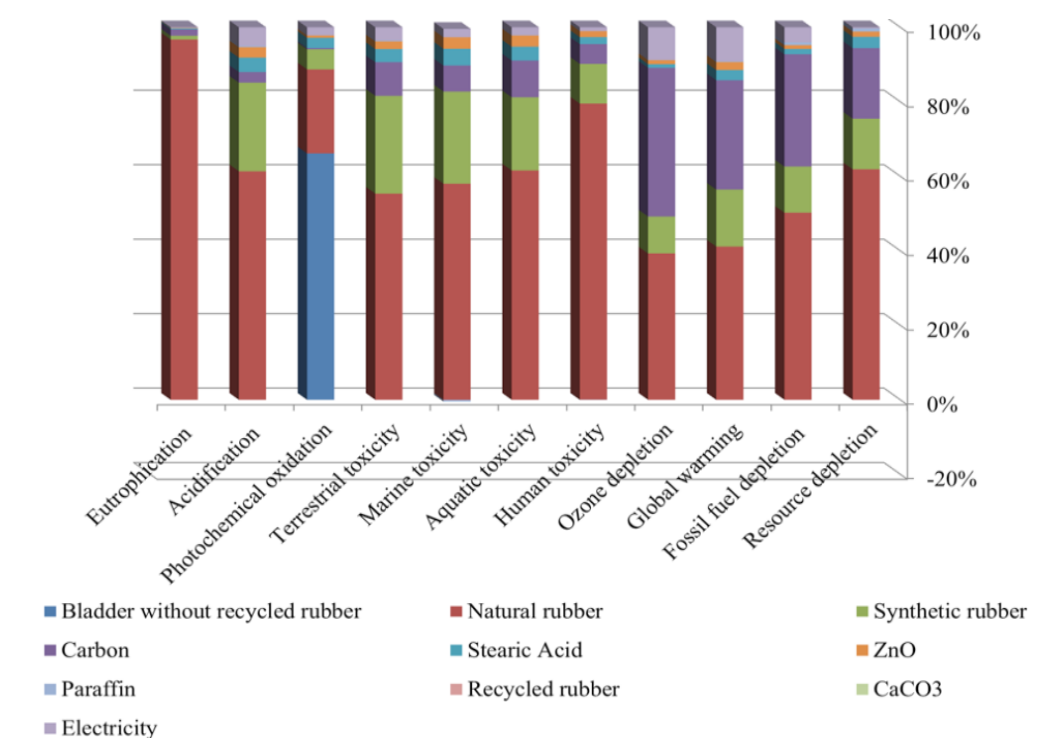

Figure 2. Environmental flow of $1 \mathrm{Kg}$ of ball bladder produced without recycled rubber

rubber in sports ball manufacturing. Firstly, it reduces the adverse environmental impacts of waste rubbers. Secondly, it helps optimize the exploitation of environmental resources of natural rubber.

Bladder production by using recycled rubber was much more eco-friendly than without recycled rubber. Natural rubber had higher contributions to all impact categories either with or without recycled rubber during the two processes of bladder forming. However, its lowest contribution was related to the resource depletion during both processes, mainly because its raw materials is extracted by making a small scratch on the tree's bark without the need to cut the tree. Moreover, its contribution to the resource depletion is further reduced by using it in combination with recycled rubber. However, blad- der with both recycled and natural rubbers had a $100 \%$ contribution to the impact category of photochemical oxidation, due to the reaction of the primary air pollutants to sunlight.

\section{Conclusion}

The ball bladder with natural rubber had a $100 \%$ contribution to 10 out of 11 impact categories except in the photochemical oxidation $(90 \%)$. In contrast, bladder with both recycled and natural rubbers had lower contributions to all impact categories, where the lowest level was related to the eutrophication $(59.3 \%)$. The ball bladder with natural rubber had highest contribution to the ozone layer depletion and global warming categories. In contrast, bladder with both recycled and natural rubbers

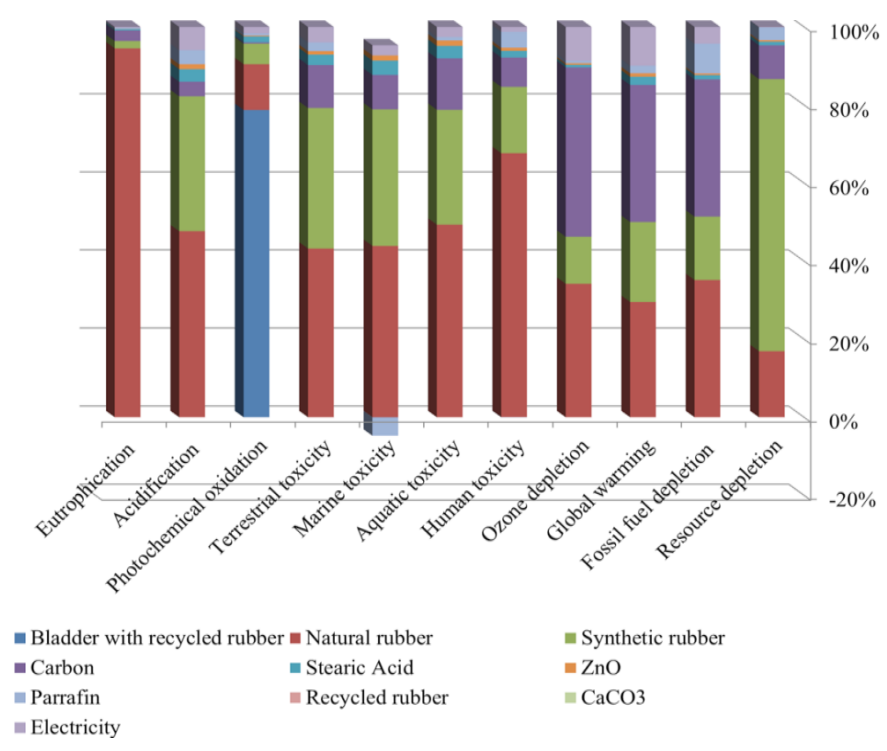

Figure 3. Environmental flow of $1 \mathrm{Kg}$ of ball bladder produced with recycled rubber 


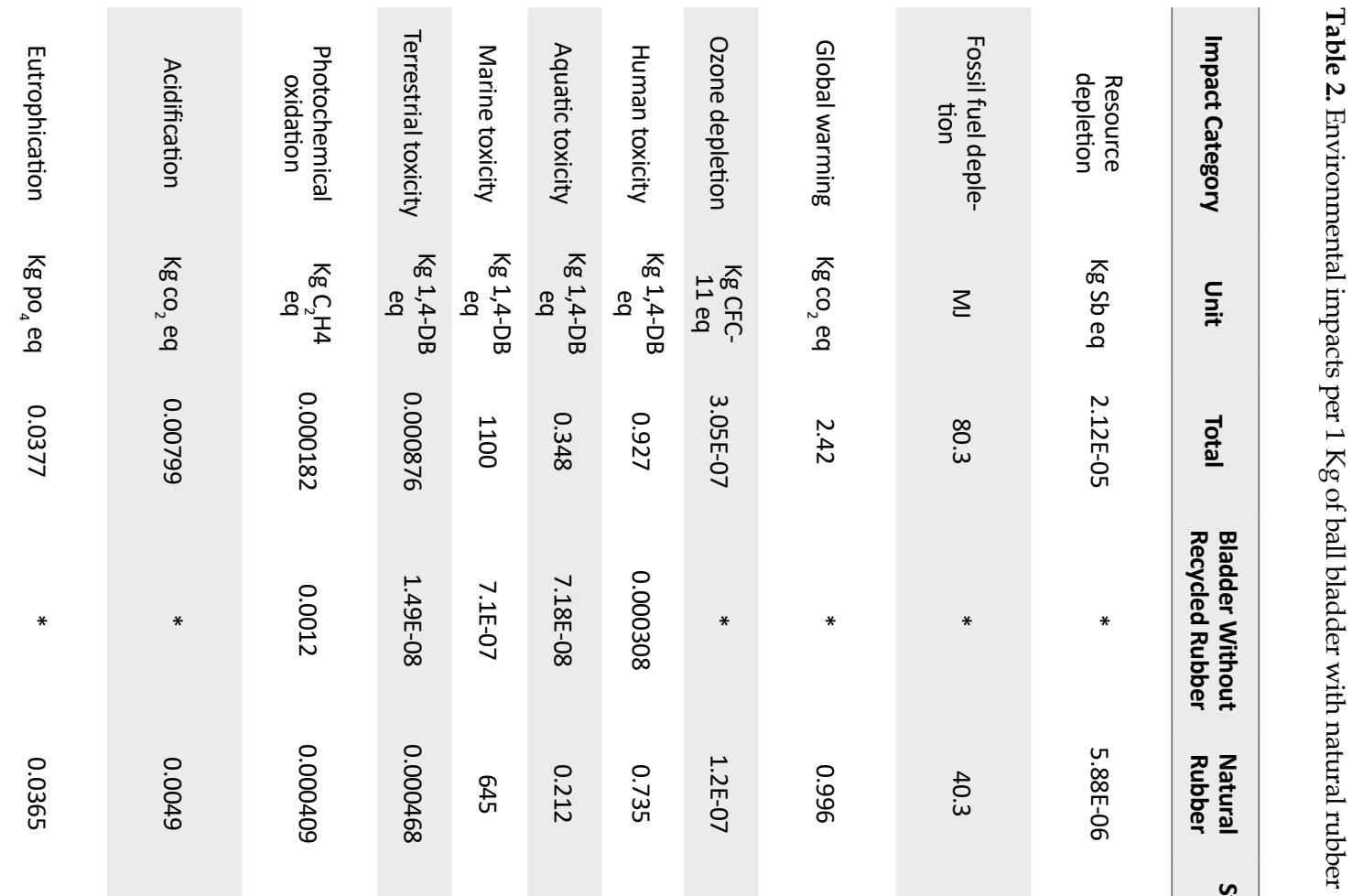

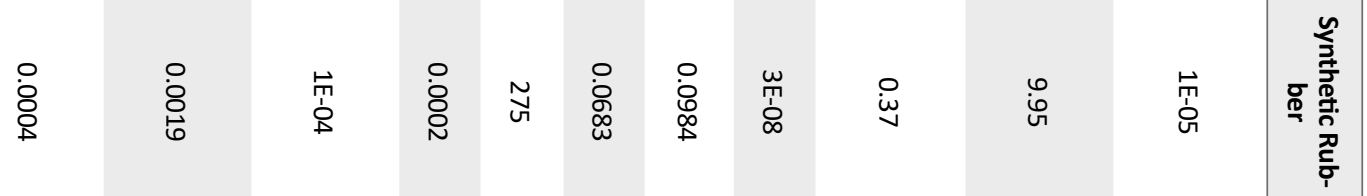

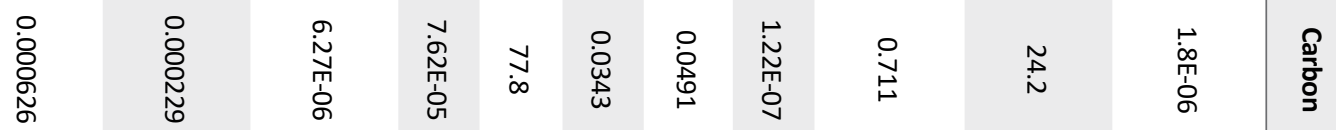

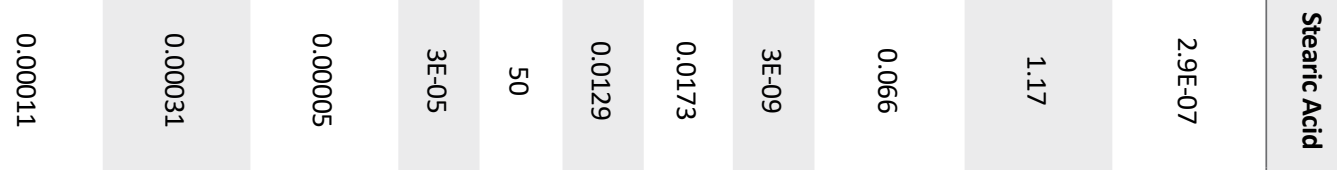

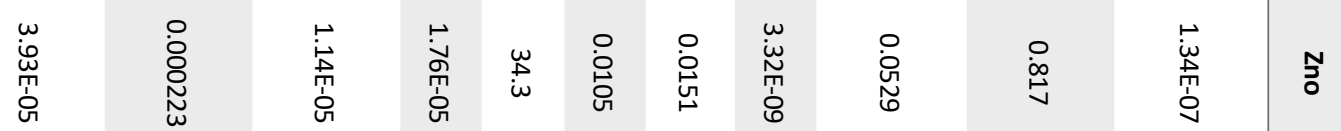

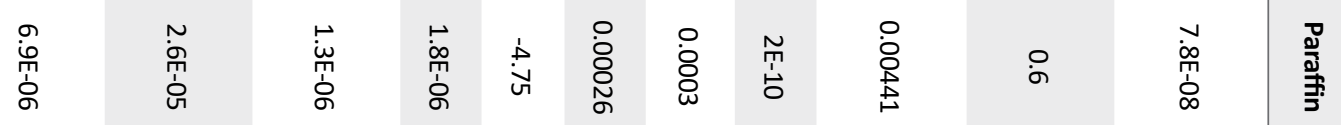

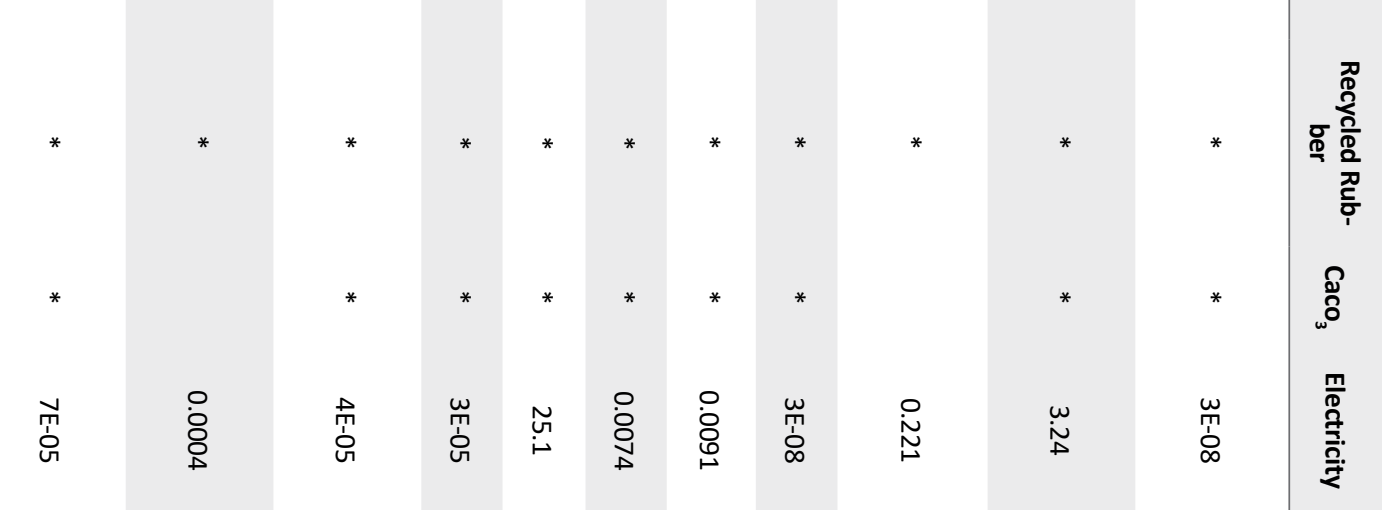




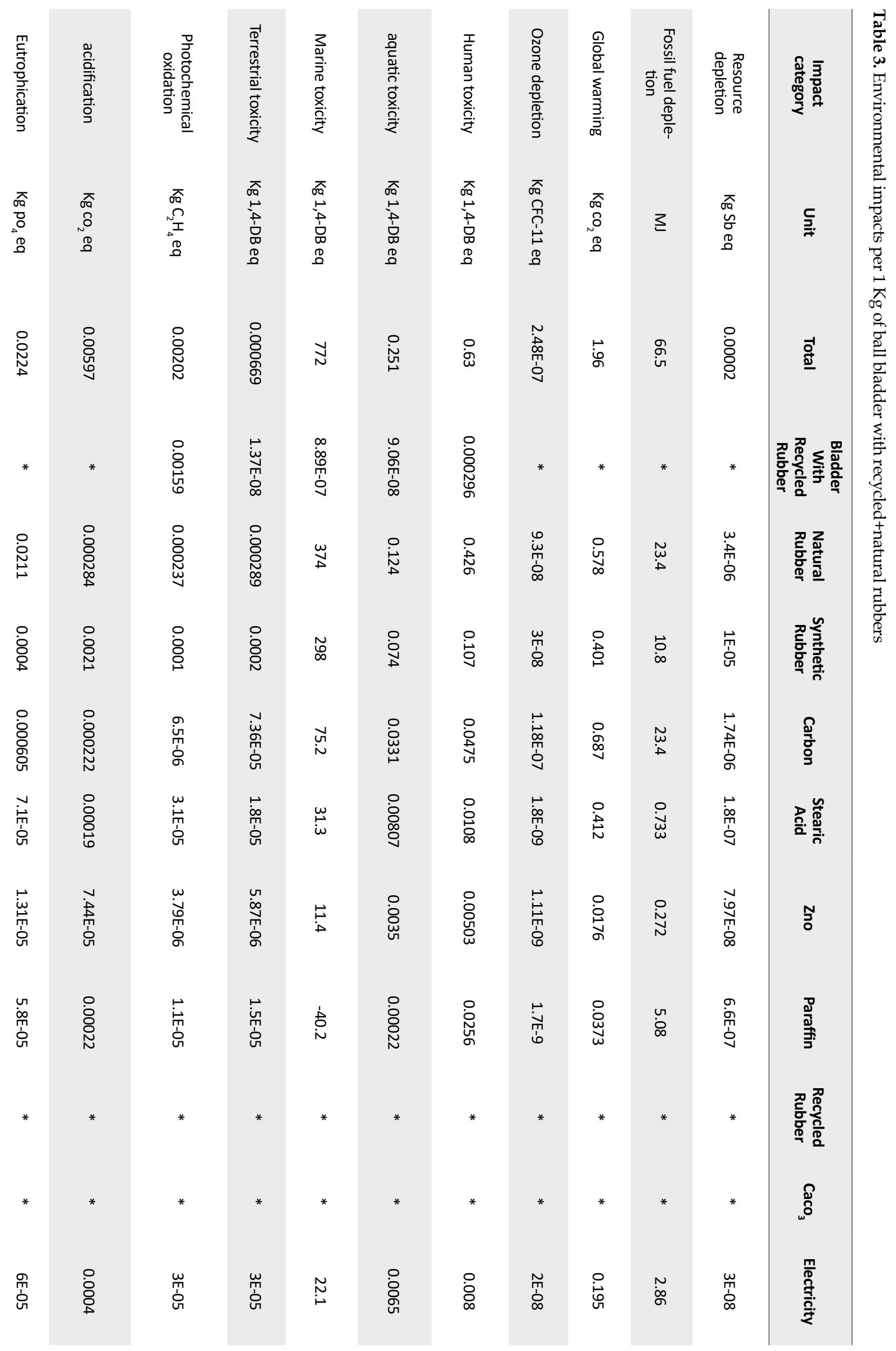




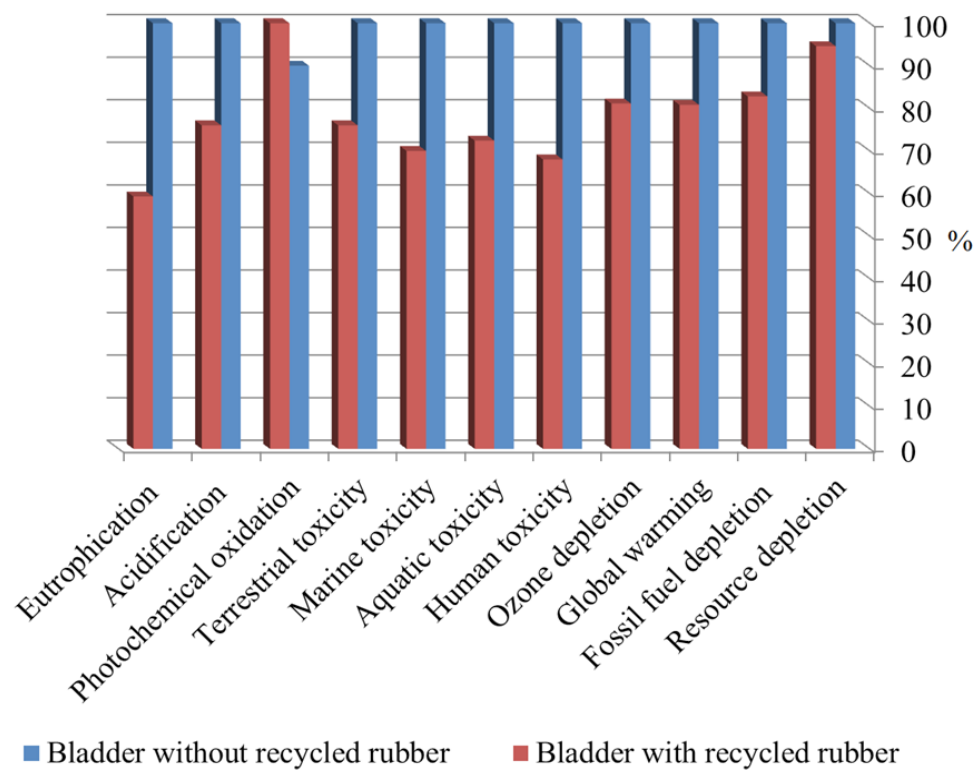

Figure 4. Comparing the environmental impacts of $1 \mathrm{Kg}$ of ball bladder with and without recycled rubbers

had an impact of $27.9 \%$ and $29.5 \%$, respectively. Therefore, the ball bladder with both recycled natural rubbers is less eco-destructive and is more eco-friendly than that the one with only natural rubber. However, it should not make us complacent about the issue of waste rubbers. It is recommendable to conduct more studies on how to minimize the use of natural rubber in ball manufacturing without any negative impact on its quality in order to minimize its adverse environmental impacts.

\section{Ethical Considerations}

\section{Compliance with ethical guidelines}

There were no ethical considerations to be considered in this research.

\section{Funding}

This article was extracted from project of the first author conducted at Islamic Azad University of Ardebil Branch, Iran.

\section{Authors' contributions}

Both authors equally contributed to preparing this article.

\section{Conflict of interest}

The authors declared no conflict of interest.

\section{Acknowledgments}

The authors would like to thank the Islamic Azad University of Ardebil Branch for supporting this research project.

\section{Reference}

[1] ISO. ISO 14044. Environmental management - Life cycle assessment - Requirements and guidelines [Internet]. 2006 [Updated 2016]. Available from: https://www.iso.org/standard/38498.html

[2] Ahmadi M, Yazdani R. [Surveying the influence of reclaimed rubber and rubber powder on physical, dynamical and processing properties of NR/BR compound) (Persian)]. Iran J Polym Sci Technol. 2008; 21(3):217-23. http://jips.ippi. ac.ir/article_752.html?lang=fa

[3] PRé Sustainability. Sustainability software for fact-based decisions [Internet]. 2021. [Updated 2021]. Available from: https://pre-sustainability.com/solutions/tools/simapro/

[4] Darestani Farahani T, Bakhshandeh GH, Barati A. [Investigating the use of recycled rubber in tire manufacturing (Persian)]. Iran Rubber Mag. 2006; 11(42):61-5. https:/ / www.magiran.com/paper/366536

[5] Fiksel J, Bakshi BR, Baral A, Guerra E, DeQuervain B. Comparative life cycle assessment of beneficial applications for scrap tires. Clean Technol Environ Policy. 2010; 13(1):19-35. [DOI:10.1007/s10098-010-0289-1]

[6] Li W, Wang Q, Jin J, Li S. A life cycle assessment case study of ground rubber production from scrap tires. Int J Life Cycle Assess. 2014; 19(11):1833-42. [DOI:10.1007/s11367-014-0793-3] 
[7] Tootoonchi H, Mahdavian M, Deihim M. [Application of rubber powder in tire industry while maintaining quality and reducing prices (Persian)]. Iran Rubber Mag. 2010; 15(59):170. https://www.magiran.com/paper/804684

[8] Dekamin M. [Assessment of environmental consequences of aquaculture systems (cold water aquaculture complexes) in Iran by using LCA (Persian)]. [MA. thesis]. Tehran: Shahid Beheshti University; 2012.

[9] Feraldi R, Cashman C, Huff M, Raahauge L. Comparative LCA of treatment options for US scrap tires: Material recycling and tire-derived fuel combustion. Int J Life Cycle Assess. 2013; 18(3):613-25. [DOI:10.1007/s11367-012-0514-8]

[10] Machado AP, Urbano L, Brito AG, Janknecht P, Salas JJ, Nogueira R. Life cycle assessment of wastewater treatment options for small and decentralized communities. Water Sci Technol. 2007; 56(3):15-22. [DOI:10.2166/wst.2007.497] [PMID]

[11] Parsajou H, Fataei E. Environmental assessment of the life cycle of sludge treatment systems of ardabil and khalkhal wastewater treatment plants. Amirkabir J Civ Eng. 2019; 51(2):243-56. [DOI:10.22060/ceej.2018.13342.5384]

[12] Mohammadi M, Fataei E. Comparative life cycle assessment of municipal wastewater treatment systems: Lagoon and activated sludge. Caspian J Environ Sci. 2019; 17(4):327-36. [DOI:10.22124/CJES.2019.3806] 